\title{
ABECEDÁRIO DA INCLUSÃO: entrecruzando memória e formação docente
}

\author{
Michele Pereira de Souza da Fonseca \\ Erika Souza Leme \\ Resumo
}

O presente artigo tem como objetivo apresentar a análise das memórias de experiências excludentes dos professores/as, como elemento formativo, desenvolvido no Curso de pós-graduação em Educação Física escolar na perspectiva inclusiva. Este estudo é parte de uma pesquisa, cujo eixo central busca compreender os processos de inclusão/exclusão na formação/ação de professores de Educação Física. Neste artigo, apresentamos o Abecedário da Inclusão estruturado em pressupostos teórico-metodológicos que confrontam as bases sociais que forjam cotidianamente a exclusão. Trata-se de uma pesquisa qualitativa, contando com 19 docentes em formação continuada, que consentiram em rememorar suas experiências passadas na fase de escolarização. Os principais resultados apontaram a necessidade de se elaborar as "marcas" das exclusões vividas no passado para que se possa admitir um porvir sem a reprodução de estereótipos, rótulos e preconceitos, dando força, sentido e materialidade em um fazer político-pedagógico que se identifica e se relaciona com os valores humanitários da inclusão.

Palavras-chave: educação física; formação docente; memória e experiência.

ABC OF INCLUSION: intersecting memory and Teacher Education

\begin{abstract}
This article aims to present the analysis of the memories of exclusionary experiences of teachers, as a formative element, developed in the Postgraduate Course School Physical Education in the inclusive perspective. This study is part of a research, whose central axis seeks to understand the processes of inclusion/exclusion in the training/action of Physical Education teachers. In this article, we present the Abc of inclusion structured in the theoretical and methodological references that confront the social bases that forge exclusion on a daily basis. It is a qualitative research, with the participation of 19 teachers in continuing education, who consented to recall their past experiences in the schooling phase. The main results pointed out the need to elaborate the "marks" of exclusions experienced in the past so that it is possible to admit a future without the reproduction of stereotypes, labels and prejudices, giving strength, meaning and materiality in a politicalpedagogical activity, identified and related to the humanitarian values of inclusion.
\end{abstract}

Keywords: physical education; teacher education; memory and experience.

\section{ABC DE INCLUSIÓN: memoria y formación docente entrelazadas}

Resumen

Este artículo tiene como objetivo presentar el análisis de las memorias de experiencias de exclusión de los docentes, como elemento formativo, desarrollado en el Postgrado de especialización en Educación Física en la perspectiva inclusiva. Este estudio es parte de una investigación, cuyo eje central busca comprender los procesos de inclusión/exclusión en la formación/acción de los docentes de Educación Física. En este artículo, presentamos el Abc de inclusión estructurado en referencias teóricas y metodológicas que confrontan las bases sociales que forjan la exclusión diariamente. Se trata de una investigación cualitativa, con la 
participación de 19 maestros en educación continua, quienes consintieron en recordar sus experiencias pasadas en la fase escolar. Los principales resultados señalaron la necesidad de elaborar las "marcas" de exclusiones experimentadas en el pasado para que sea posible admitir un futuro sin la reproducción de estereotipos, etiquetas y prejuicios, dando fuerza, significado y materialidad en una actividad político-pedagógica que se identifica y se relaciona con los valores humanitarios de inclusión.

Palabras clave: educación física; formación del profesorado; memoria y experiencia.

\section{INTRODUÇÃO}

Movidas pela infindável luta pelo direito à Educação pública, crítica, democrática e pelo reconhecimento e valorização das diferenças, nos lançamos à reflexão sobre a formação continuada de professores na e para perspectiva inclusiva, considerando suas memórias como elemento-chave do processo formativo, pela possibilidade de aguçar a sensibilidade, a escuta e a experiência com o outro e, consequentemente, a compreensão de mundo e de si próprio de maneira mais alargada, a fim de tensionar as instâncias "útil" e "técnica" que vêm sendo defendidas pela lógica produtivista e de aligeiramento da formação humana.

O presente estudo é parte de uma pesquisa em desenvolvimento, cujo eixo central objetiva compreender os processos de inclusão/exclusão na formação/ação de professores/as de Educação Física. Um dos sub eixos desenvolvidos aborda a formação continuada, que tem como objeto de estudo o Curso de Pós-graduação Especialização em Educação Física Escolar na perspectiva inclusiva, vinculado à Escola de Educação Física e Desportos da Universidade Federal do Rio de Janeiro (EEFD-UFRJ). Os achados do eixo central da pesquisa apontam lacunas na trajetória formativa com relação a formação na e para perspectiva inclusiva e que se desdobram na ação docente no chão da escola.

Com vistas a aprofundar a compreensão de algumas dessas lacunas, desenvolvemos o presente artigo que tem como objetivo apresentar uma análise das memórias de experiências excludentes dos/as professores/as como elemento formativo do Curso de Pós-graduação Especialização em Educação Física Escolar na perspectiva inclusiva, a partir da construção do Abecedário da Inclusão. Neste caso, a produção em questão foi construída em quatro etapas: de sensibilização do tema, rememoração das experiências de vida escolar, de elaboração de sentidos e significados por meio do registro individual e, por fim, a partilha coletiva. Esse processo foi desenvolvido no primeiro encontro com a turma, de modo que, os dados aqui apresentados foram produzidos pelos docentes (estudantes do curso em tela) na disciplina Aspectos legais: políticas de inclusão, que objetiva discutir as políticas públicas da Educação Inclusiva e da Educação Especial nos âmbitos internacional e nacional com o intuito de provocar a reflexão e a autorreflexão das experiências vividas no seio escolar, a fim de mobilizar a compreensão das bases objetivas que forjam subjetividades frágeis e autoritárias e com isso alavancar ações calcadas nas relações de solidariedade, coletividade, de cooperação, de livre pensar, sentir e agir.

Assim, intencionando aprofundar e produzir conhecimento com os/as professores/as, lançamos mão do estudo de narrativa ligada à história de vida, por se tratar de uma modalidade de pesquisa que valoriza a expressão dos pensamentos dos indivíduos acerca de sua visão de mundo. Conforme, Bolívar, Domingo e Fernández (2001), a investigação narrativa baseia-se em uma epistemologia construtivista e interpretativa, que defende a narrativa como estrutura central do modo como os humanos constroem os sentidos e os significados do curso de vida e a identidade pessoal e que, portanto, as narrativas culturais e individuais estão interligadas.

Partimos do pressuposto de que a experiência humana é contextualizada, por isso só pode ser interpretada de maneira qualitativa. Cada indivíduo rememora suas vivências passadas imersas 
em uma rede de significações e singularidades, trazendo consigo marcas desse tempo vivido para seu contexto atual - profissional e que, hoje, constituem este/a professor/a e suas subjetividades. Apostamos que se os docentes alcançarem essa compreensão de si no mundo serão capazes de mudar suas concepções e práticas. Diante disso, tomamos o estudo das narrativas como fundamental para aceder a Inclusão em Educação.

O exercício de pensar, provocar e valorizar a memória, traz à tona preconceitos, modelos idealizados e estigmas naturalizados socialmente, decorrentes da dificuldade de lidar com características distintas e peculiares diferentes das valorizadas socialmente. De modo que, elaborar experiências pode funcionar como um antídoto contra a indiferença e a inércia reprodutora das exclusões fomentadas pela razão instrumental, tendo em vista que o processo formativo cruza, à sua maneira, à temática da identidade para si e para os outros, dando centralidade aos encontros e desencontros medeados pelas palavras. Como aponta Larrosa:

[...] as palavras produzem sentidos, criam realidades e às vezes, funcionam como potentes mecanismos de subjetivação. Eu creio no poder das palavras, na força das palavras, creio que fazemos coisas com as palavras e, também, que as palavras fazem coisas conosco. As palavras determinam nosso pensamento porque não pensamos com pensamentos, mas com palavras, não pensamos a partir de uma suposta genialidade ou inteligência, mas a partir de nossas palavras. E pensar não é somente "raciocinar" ou "calcular" ou "argumentar", como nos tem sido ensinado algumas vezes, mas é sobretudo dar sentido ao que somos e ao que nos acontece (LARROSA, 2003a, p. 20-21).

Como contraponto a cisão entre indivíduo e sociedade, nos voltamos aos conceitos de memória, narrativa e experiência como elementos potencializadores de um processo formativo na perspectiva da inclusão em Educação, reafirmando os preceitos da Declaração de Salamanca (UNESCO, 1994, p. 4):

O desafio que confronta a escola inclusiva é no que diz respeito ao desenvolvimento de uma pedagogia centrada na criança e capaz de bem sucedidamente educar todas as crianças, incluindo aquelas que possuam desvantagens severas. O mérito de tais escolas não reside somente no fato de que elas sejam capazes de prover uma educação de alta qualidade a todas as crianças: o estabelecimento de tais escolas é um passo crucial no sentido de modificar atitudes discriminatórias, de criar comunidades acolhedoras e de desenvolver uma sociedade inclusiva (grifo nosso).

São essas aberturas e potências em devir que sustentam o processo formativo na e para perspectiva inclusiva, que entrelaça as experiências formativas com as humanas, ensejando ações combativas frente ao mundo competitivo e enrijecido, convocando nos professores/as suas memórias, histórias e palavras, ou seja, a produção de narrativas que confluam com a vida de todas e todos. Indo ao encontro das palavras de Larrosa (2003b, p.197):

Uma imagem do outro é uma contradição. Mas talvez nos reste uma imagem do encontro com o outro [...] E isso na medida em que esse encontro não é nem apropriação, nem um mero reconhecimento em que se encontra aquele que já sabe e que já tem, mas um autêntico cara a cara com o enigma, uma verdadeira experiência, um encontro com o estranho e com o desconhecido, o qual não pode ser reconhecido nem apropriado.

Esse exercício formativo se apresenta como componente fundamental de enfrentamento à incapacidade de experiência formativa presente na contemporaneidade, que tem relação com a 
ausência da memória individual e histórica do tempo vivido e da pobreza da experiência. Em seu lugar se instala o tempo aligeirado do momento atual, das respostas fugazes em relação às pessoas e aos acontecimentos. De acordo com Horkheimer (2002, p.43), "a rápida apreensão dos fatos substitui a penetração intelectual do fenômeno da experiência".

Exatamente por isso, ressaltamos a importância da formação se dar na e para perspectiva inclusiva, a fim de fortalecer a racionalidade sensível e crítica, capaz de mobilizar outros modos de ser e fazer docência na relação com o outro, na qual caibamos todas/os e inteiras/os, com nossas diferenças e anseios. Notadamente, a Educação deve ser vista como uma atitude permanente de transformação da própria consciência individual e coletiva, ou seja, para a autorreflexão crítica como forma contundente de luta contra o ódio, preconceito e as exclusões de todas as ordens, porque:

[...] O ensino não deveria consistir apenas em aprender a escolher o que é certo, e na apreensão do mesmo por meio de categorias, mas, desde o início, este ensino deveria desenvolver as aptidões críticas; ele deveria conduzir as pessoas, por exemplo, à capacidade de desmascarar ideologias, [tentativa de incutir nas pessoas uma falsa consciência e um ocultamento da verdade] deveria protegê-las ante identificações falsas e problemáticas, protegendo-as, sobretudo em face da propaganda [em] geral. A formação a que nos referimos consistiria em pensar problematicamente conceitos como estes em sua positividade, possibilitando adquirir um juízo independente e autônomo a seu respeito (ADORNO, 2010, p.7980).

Essas considerações são fundamentais para estruturarmos uma formação docente que lide com os impactos de como os professores percebem a si mesmos e ao seu trabalho. Nesse lugar reside nossa preocupação em discutir a formação continuada de professores/as trazendo à tona suas inquietações, anseios, experiências e memórias refazendo seu percurso, nutrindo novos significados às experiências passadas, reformulando as práticas presentes, construindo o futuro com subjetividades inclusivas e democráticas.

\section{A FORMAÇÃO DOCENT'E NA E PARA PERSPECTIVA INCLUSIVA: O CURSO DE PÓS-GRADUAÇÃO EM TELA}

Considerando as discussões envolvendo formação e inclusão, Fonseca (2014) vem desenvolvendo a ideia de pensar numa formação na e para perspectiva inclusiva, para afirmar a relevância de formar professores e professoras para lidar com as diferenças em suas ações profissionais, mas também de perceber se eles, enquanto seres singulares, são considerados na formação.

O pensamento mais imediato, no que tange a formação docente, tem sido de mobilizar olhares sensíveis e pensantes que oportunizem lidar com os desafios de uma ação docente inclusiva. Daí porque ser fundamental pensar no sentido de uma formação que considere as discussões, as experiências e concepções singulares daqueles sujeitos participantes e as trocas que são promovidas, de modo a desenvolver o sentimento de pertença no processo, que sejam respeitados e considerados nas suas demandas específicas. Dessa forma, há que se considerar as questões potenciais de exclusão/inclusão que ocorrem na formação, durante seu percurso formativo inteiro, tendo um olhar atento para o reflexo dessa formação nas futuras ações docentes desse professor/a.

A formação docente na e para perspectiva inclusiva (FONSECA, 2014) se funda num exercício de reflexão e autorreflexão que busca provocar a desconstrução de uma formação docente 
eminentemente técnica e pragmática, e que seja ancorada no sentido reflexivo, crítico e transformador (NÓVOA, 2002; 2017). Nóvoa (1995), ao considerar que os professores precisam se assumir como produtores da sua própria profissão, também nos dá subsídios a pensar sobre a importância de revisitar as experiências vividas que o forjam na docência, que atravessam e são atravessadas por suas histórias vividas.

O professor é a pessoa. E uma parte importante da pessoa é o professor (Nias, 1991). Urge por isso (re)encontrar espaços de interacção entre as dimensões pessoais e profissionais, permitindo aos professores apropriar-se dos seus processos de formação e dar-lhes um sentido no quadro das suas histórias de vida (NÓVOA, 1995, p.25).

Esse princípio da formação na e para perspectiva inclusiva se materializa no curso de Pósgraduação lato sensu, gratuito, Educação Física escolar na perspectiva inclusiva, vinculado à EEFDUFRJ. Considerando a atual conjuntura brasileira, marcada fortemente pela tentativa de imposição de profundos retrocessos e por intensos ataques aos direitos trabalhistas e à Educação pública, universal e laica, este curso se coloca como fortalecimento da resistência, superando a dicotomia entre o político e o pedagógico, em prol de uma Educação crítica, democrática e gratuita. Nesse sentido, o curso foi concebido para promover a formação continuada de professores/as de Educação Física, aprofundando e ampliando saberes, a fim de atender às premências frente aos processos de inclusão/exclusão na Educação Física escolar na perspectiva democrática de Educação.

Em consonância com a luta pela existência, resistência e insurgência da Educação pública, esse curso de Pós-graduação emerge do reconhecimento da demanda da formação pela afirmação do conhecimento acadêmico entrelaçado com a escola básica. Além disso, lacunas na formação inicial nessa área reforçam que há pouco espaço de discussão de outras abordagens envolvendo inúmeros processos de inclusão/exclusão de professores de Educação Física, além de marcas de um histórico excludente pautado em principios militaristas, eugenistas e higienistas (FONSECA, 2009; 2014, GÓIS JUNIOR, 2013).

Assim, o referido curso se ancora numa perspectiva ampla de inclusão, processual, infindável e dialética (SAWAIA, 2017, BOOTH E AINSCOW, 2011, CROCHICK, 2011), englobando quaisquer necessidades específicas dos/as estudantes, no sentido de uma Educação emancipadora, refutando padrões de massificação e rompendo com os modelos e estereótipos sociais. Portanto, para além de discutir as questões relativas às deficiências, transtorno do espectro autista e altas habilidades/superdotação, amplia o olhar sobre o conceito de inclusão em Educação, para as exclusões de toda ordem que ocorrem cotidianamente no âmbito social e institucional e para os desdobramentos para a prática pedagógica em Educação Física escolar.

Considerando esse referencial, enfatizamos no curso as políticas públicas nesse contexto e a relação da formação com temas candentes na sociedade, que se refletem nos desafios da escola e da Educação Física escolar, como bullying, gênero e sexualidade, racialidade, etnia e religiosidade, a especificidade da Educação de jovens e adultos e de estudar casos de inclusão/exclusão experienciados pelos estudantes do curso em suas práticas docentes. Também há espaço para problematização da Educação Física e inclusão em ação na escola no que tange à criatividade, à ludicidade, à criticidade e ao planejamento e avaliação na perspectiva inclusiva, permeados pela concepção contemporânea de Educação Física, que se distancie dos modelos tecnicistas e meramente biologizantes e que amplie o conceito de participação nas aulas, abrangendo a todos/as estudantes.

Com base nesses desafios, inquieta-nos pensar acerca de uma formação que afirme as diferenças, entendendo a formação docente, para além de uma capacitação como uma preparação prévia meramente técnica-metodológica para o trato dessas questões, "e sim, a um preparo atitudinal, 
crítico, cidadão, investigativo, criativo e desarmado" (FONSECA, 2009, p. 25) e, sobretudo, reflexivo.

O curso, iniciado em 2017, está atualmente na $2^{a}$ turma, tem duração de 18 meses e 420 horas. A despeito das dificuldades estruturais e políticas de se manter um curso dessa natureza, foram abertas 30 vagas em cada turma, sendo 6 obrigatoriamente oferecidas na forma de cotas de ações afirmativas. A turma de 2019, que participa deste estudo, é composta por 30 estudantes, 4 egressos de universidades privadas e 26 de universidades públicas; desses, 10 autodeclarados negros e 2 com deficiência visual (1 com baixa visão e 1 cego). Dez atuam no ensino público, os demais atuam no ensino privado, projetos sociais, ou no ambiente não formal de ensino. Para esse estudo, 19 estudantes do curso da turma de 2019 se disponibilizaram a participar do abecedário. Vale ressaltar que os participantes (professores em formação continuada) são licenciados em Educação Física. Uma parcela significativa tem experiência docente atuando na educação básica e outra é composta por graduandos recém-formados, que na graduação tiveram a oportunidade de participar de projetos de ensino e extensão voltados à inclusão escolar e iniciação à docência.

Diante da diversidade do grupo, entendemos ser primordial desenvolver um trabalho de reflexão e autorreflexão a partir da rememoração das "marcas" que nos constituem, centrado na formação de si e, por conseguinte, do profissional sensibilizado, pensante e com posicionamento crítico sobre ser e fazer docência em uma sociedade tão desigual e excludente como a nossa, construindo coletivamente o abecedário como parte das atividades desenvolvidas na disciplina Aspectos legais: políticas de inclusão.

A despeito de ser uma atividade de sala de aula e os 30 pós-graduandos terem participado, é importante ressaltar que apenas 19 consentiram na divulgação de suas produções.

A imersão sobre o Abecedário da Inclusão como material de produção de conhecimento implicou na pré-análise dos registros, cuja leitura permitiu a organização de categorias de análise à luz do referencial Teoria Crítica da sociedade, que nos orientam na discussão acerca do entrecruzamento de suas memórias de experiências excludentes e formação docente, sendo elas: a) Julgamento ao atributo físico fora do padrão socialmente imposto; b) Questões de gênero e sexualidade; c) Racismo; d) Julgamentos excludentes subjetivos movidos pela razão instrumental.

\section{ABECEDÁRIO DA INCLUSÃO}

De acordo com o dicionário ${ }^{1}$, a palavra abecedário significa um conjunto de letras de um sistema de escrita, segundo uma ordem convencionada. Já o Abecedário da Inclusão é construído e, portanto, constituído pelos sentimentos humanos, de um estado de espírito que descreve um fato. Diante disso, o Abecedário da Inclusão ${ }^{2}$ aqui apresentado é relacional, conjuntural e personalíssimo, jamais uma lista, mas sim como algo que se dá entre e com, na relação de convívio entre e com as pessoas, em momentos específicos, em lugares distintos, mesmo que comuns.

Nesse sentido, nos debruçamos sobre a memória na perspectiva da experiência (BENJAMIN, 1994), para quem a memória compõe uma coleção de narrativas que trazem à tona a experiência pessoal passada, capaz de ser atualizada a partir de interpretações, posto que, a narração é uma forma de exteriorizar nossas experiências que ficam marcadas em nossa memória individual e

\footnotetext{
${ }^{1}$ Ebook Dicionário Houaiss da Lingua Portuguesa PDF Online by Ebook, Pdf, Kindle.

${ }^{2}$ Inspiradas no Abecedário de Gilles Deleuze, uma realização de Pierre-André Boutang, produzido pelas Éditions Montparnasse, Paris. No Brasil, foi divulgado pela TV Escola, Ministério da Educação. Tradução e Legendas: Raccord [com modificações]. Disponível em: http://escolanomade.org/wp-content/downloads/deleuze-o-abecedario.pdf. Acessado em: 5 jan. 2020.
} 
coletiva. Isso explica a referência aos lampejos de memórias, compreendidos como imagens fugazes de um tempo, em que se deu um gesto ou palavra que vive no céu escuro da memória, a fim de entender como essas experiências operam em nossa singularidade constitutiva. Esta potência se expressa no processo dialético deste exercício, tal como explicitado por Benjamin (2006, p. 504):

Não é que o passado lance luz sobre o presente ou que o presente lance sua luz sobre o passado; mas a imagem é aquilo em que o ocorrido encontra o agora num lampejo, formando uma constelação. Pois, enquanto a relação do presente com o passado é puramente temporal e contínua, a relação do ocorrido com o agora é dialética - não é uma progressão, e sim uma imagem que salta.

A fim de aflorar a memória e as palavras, iniciamos o exercício reflexivo lendo o livro, Correspondência, escrito por Bartolomeu Campos de Queirós (QUEIRÓS, 2004). Criado como se fossem bilhetes entre garotos e garotas, ele fala de palavras para adormecerem em dicionários e de palavras para acordarem. Assim, inspirados, propusemos o exercício de rememorar palavras que marcaram suas vidas na fase de escolarização e, tal como Bartolomeu, que fossem palavras para serem adormecidas no dicionário, por se tratarem de palavras que machucaram e provocaram dor, indiferença e frieza.

Vale ressaltar que "O medo de se machucar, o medo de ser destruído. Esse medo endurece a percepção que só consegue se fixar em um único sentido, para uma única direção, não possibilitando assim perceber diversos pontos de vista" (CROCHÍCK, 2015, p.33). Essa barbárie civilizada é diagnosticada por Adorno (2010, p.30), como a "indiferença ao menos embrutecida e amedrontada".

Isso porque o passado irresolvido resiste à representação e limita a capacidade de agir no presente. Daí a necessidade de criação de novas narrativas, rememorar e elaborar e perlaborar, a fim de definirmos outras possibilidades de ver, sentir, estar e organizar o mundo de maneira a afirmar e considerar as diferenças.

A partir do exercício proposto, apresentamos o Abecedário da Inclusão, formado por um conjunto de memórias e histórias de vida:

Adotado - do biológico não se forjou. Mas a história foi modificada...porque o amor se consolidou, supriu uma ausência de maneira inusitada.

Bochecha - uma simples parte do corpo que me revelou a maldade das pessoas e passar a me sentir insatisfeita comigo mesma.

Coitadinho - sentimento de pena baseado em preconceitos.

Chokito - não é chocolate, são minhas espinhas.

Devagar - não se trata de algo suave e sem pressa e, sim, uma crítica e um julgamento.

Gorda - fora do padrão, mas cabe dentro de um abraço.

Incapaz - em vários momentos o silêncio julga e revela o preconceito.

Indiferença - mudança do tanto faz para o muito faz.

Homofobia - expressa o indivíduo sem empatia que precisa inferiorizar o outro por uma característica que ele não escolheu.

Lerda - quando uma pessoa não corresponde às expectativas de outras.

Macaquinho - criança negra quando faz arte.

Magrela - fitness demais.

Menininho - menina que faz coisas de menino.

Mimimi - utilizada como forma desprezo e/ou atribuição de insignificância a alguém ou alguma coisa.

Mulata - não dá pra ser Paquita, mas dá pra escola de samba. 
Opinião - não se dá, só fere.

Piranha - quando a mulher toma as mesmas atitudes de um homem.

Política - "você não sabe o que está falando menina".

Solidão - perda e vazio na multidão.

O Abecedário da Inclusão é formado por palavras singelas, mas fortes, que habitam em nós, e se movem entre o ontem e o hoje, ganhando novos significados na história da vida de cada um no mundo. Isso porque não existem memórias sem experiência social, apesar de a experiência ser vivida e sentida subjetivamente, ela é ao mesmo tempo interpessoal, ou seja, compartilhada culturalmente. Por conta disso, as representações expostas no Abecedário nos conduzem a vários prismas de análise, dentre esses, destacamos os de âmbito sócio-histórico-cultural.

À luz do referencial teórico, apresentamos as categorias de análise, a fim de lapidar o material empírico com vistas a produzir conhecimento alicerçado na formação na e para a perspectiva inclusiva, pois lidamos com as experiências vividas de modo dialético, revelando as conexões entre o mim e outro, o individual e o coletivo e relação da subjetividade com a objetividade posta.

a) Julgamento ao atributo físico fora do padrão socialmente imposto:

Bochecha - uma simples parte do corpo que me revelou a maldade das pessoas e passar a me sentir insatisfeita comigo mesma.

Chokito - não é chocolate, são minhas espinhas.

Gorda - fora do padrão, mas cabe dentro de um abraço.

Magrela - fitness demais.

Esses relatos demostram uma realidade cruel em que muitos são vistos e veem pela lente de um inatingível padrão de beleza físico-estético imposto pela sociedade, retratado diariamente pela mídia, amplificado nas redes sociais e reproduzido diariamente sem reflexão de o quanto isso afeta as pessoas envolvidas. Isto resulta em uma convivência superficial, que olha o outro somente por um de seus atributos físicos, desconsiderando todo o restante e resumindo a pessoa a um rótulo que magoa e exclui, indo ao encontro do pensamento de Adorno (2010, p. 150), ao afirmar que "as pessoas odeiam o que é diferenciado, o que não é moldado, porque são excluídos do mesmo e porque, se o aceitassem, isto dificultaria sua "orientação existencial".

Ao considerar a formação na e para a perspectiva inclusiva, propomos a reflexão e ressignificação das experiências que aconteceram conosco ou com pessoas próximas para desconstruir preconceitos e estereótipos excludentes e que ainda permanecem muito enraizados no nosso cotidiano. Essa foi intenção proposta a partir do abecedário, que os participantes envolvidos perlaborassem essas experiências, ou seja, um processo de elaboração interpretativa no processo de autoanálise, no qual o indivíduo enfrenta conteúdos recalcados de forma a poder considerá-los conscientemente.

b) Questões de gênero e sexualidade:

Homofobia - expressa o indivíduo sem empatia que precisa inferiorizar o outro por uma característica que ele não escolheu.

Menininho - menina que faz coisas de menino.

Piranha - quando a mulher toma as mesmas atitudes de um homem.

Política - "você não sabe o que está falando menina".

No que tange às questões de gênero, percebemos que reforçam o debate sobre a prescrição de uma única forma possível e aceitável de ser mulher, desqualificando-a ou calando a sua voz para assuntos que são tidos como adequados ou não à ela. Estamos lidando com antagonismos constituídos em um quadro estrutural mais amplo, porque para Horkheimer e Adorno (1956) a questão de gênero está imersa ao próprio antagonismo social que é percebido como heteromórfico, tal 
como acontecem nas questões de antissemitismo, sexismo, etnocentrismo, homofobia e capacitismo. Ou seja, relações que expressam a lógica irracional da sociedade de subjugação e dominação. Notadamente, a sociedade contemporânea, vê-se cada vez mais provida com esquemas prontos ao invés de se construir esquemas próprios, fruto da experiência, em relação com as coisas e em contato com o outro e consigo. Por este motivo, apostamos no processo formativo calcado na experiência, capazes de ensejar concretamente relações de gêneros igualitárias, solidárias, democráticas e inclusivas.

c) Racismo:

Macaquinho - criança negra quando faz arte.

Mulata - não dá pra ser Paquita, mas dá pra escola de samba.

Esses relatos são sequelas evidentes do racismo estrutural que assola nosso país e tem desdobramentos nas brincadeiras pejorativas que ainda tentam naturalizar a condição do negro como ser inferior, desnudando a estrutura social brasileira que ainda legitima o racismo diariamente.

O fato de parte expressiva da sociedade considerar ofensas raciais como 'piadas', como parte de um suposto espírito irreverente que grassa na cultura popular em virtude da democracia racial, é o tipo de argumento necessário para que o judiciário e o sistema de justiça em geral resista em reconhecer casos de racismo, e que se considerem racionalmente neutros (ALMEIDA, 2018, p. 59).

A não reflexão sobre tais questões levam a perpetuação de discursos e ações que adotam eufemismos para se referir a negros e negras, como "moreno/a", "mulato/a" ou "pessoa de cor", por exemplo, e principalmente de que há lugares adequados ou não para essas pessoas e a objetificação do corpo da mulher negra. Na contramão desta irracionalidade, reafirmarmos, com Adorno, a potencialidade da Educação para permitir aos indivíduos desvendarem as contradições da vida social e para conscientizá-los das possibilidades de resistência da cultura verdadeiramente humana contra a barbárie da sociedade danificada: "Essa tarefa não é para ser assumida pela Educação, ela é tarefa da Educação" (ADORNO, 2004, p. 120).

Vale lembrar que nas sociedades democráticas as ideias racistas estão em conflito com as normas não racistas da democracia. Por conta disso, identificamos uma parcela significativa de pessoas que não se considera abertamente racista, entretanto, de alguma forma, é conformista, omissa ou alheia à marginalização vivida pelas minorias, o que acaba por contribuir com a manutenção da ordem social criminosa, opressora e excludente. No caso em tela, os participantes relatam expressões direcionadas a eles que não foram entendidas naquele momento como atos racistas, mas que causaram impactos em suas trajetórias de vida com consequente reflexo na formação como docentes, posto que somente iniciaram a problematizar sobre isso anos mais tarde.

d) Julgamentos excludentes subjetivos movidos pela razão instrumental:

Adotado - do biológico não se forjou. Mas a história foi modificada...porque o amor se consolidou, supriu uma ausência de maneira inusitada.

Coitadinho - sentimento de pena baseado em preconceitos.

Devagar - não se trata de algo suave e sem pressa e, sim, uma crítica e um julgamento.

Incapaz - em vários momentos o silêncio julga e revela o preconceito. Indiferença - mudança do tanto faz para o muito faz.

Lerda - quando uma pessoa não corresponde às expectativas de outras.

Mimimi - utilizada como forma desprezo e/ou atribuição de insignificância a alguém ou alguma coisa.

Opinião - não se dá, só fere. 
Solidão - perda e vazio na multidão.

Importa refletir que tais julgamentos excludentes subjetivos, adjetivam, reduzem e desqualificam as pessoas e dessa maneira, afetam e impactam suas vidas de diversas formas. A necessidade de utilizar uma lente ampliada para compreender os processos de inclusão/exclusão ficam evidentes a partir dos dados organizados nas categorias de análises propostas para tal reflexão, pois notadamente também nos apresentam questões opressoras e que geram exclusão na nossa sociedade. Avançamos no discurso de combate às opressões de toda ordem, porém ainda há que se refletir aprofundamente sobre as práticas cotidianas, especialmente as pedagógicas.

A questão da representatividade se mostra em todos esses relatos acima, pois ainda é muito presente e significativo o ideal dominante branco, masculino e heterossexual como a principal referência de beleza e de padrão de indivíduo perfeito. A aceitação de diversas formas de ser e estar no mundo ainda é uma luta a ser vencida, e a representatividade nos ajuda a entender que temos alternativas outras que não somente o padrão imposto, tendo a possibilidade de desconstruir verdades absolutas e criar novas/outras trajetórias.

Todos esses relatos que conceberam o Abecedário da inclusão evidenciam nossa preocupação com a formação na e para perspectiva inclusiva, de modo a não desconsiderar essas experiências e memórias que marcaram (e ainda marcam) fortemente esses professores/as, mas principalmente, como estes ressignificam (ou não) tais experiências e memórias no seu fazer docente, interrompendo (ou não) um círculo vicioso excludente (FONSECA, 2014) que perdura, muitas vezes, na sua atuação na Educação Básica.

Essas ponderações são importantes para forjar um/a professor/a em constante formação crítica e reflexiva, que atenta às situações ao seu redor, que reflete sobre suas dores e busca estratégias pedagógicas para evitar a perpetuação dessas práticas excludentes, para si e para o outro. Nesse sentido, concordamos com Nóvoa (2017, p.1131) quando ele aponta que "A formação é fundamental para construir a profissionalidade docente, e não só para preparar os professores do ponto de vista técnico, científico ou pedagógico", mas sobretudo humano e inclusivo.

Nota-se que o indivíduo reificado não percebe no que se transformou e reproduz estereótipos, de tal como que equipara o ser humano a um objeto ou o reduz ao mesmo, de maneira perversa e repressora dissemina o ódio e fortalece a frieza e a indiferença. Com efeito, o componente básico desse trabalho irracional de nossa sociedade é reproduzir a penúria que é a vida para uma grande parcela da sociedade, "a escala do padrão de vida corresponde com bastante exatidão à ligação interna das classes e dos indivíduos com o sistema" (ADORNO; HORKHEIMER, 1985, p. 124).

\begin{abstract}
A resignação do pensamento, em vista da produção da unanimidade, significa o empobrecimento do pensamento bem como da experiência: a separação dos dois domínios prejudica ambos. O espírito torna-se de fato o aparelho da dominação e do autodomínio, como sempre havia suposto erroneamente a filosofia burguesa. Os ouvidos moucos, que é o que sobrou aos dóceis proletários desde os tempos míticos, não superam em nada a imobilidade do senhor. É da imaturidade dos dominados que se nutre a hipermaturidade da sociedade. A regressão das massas, de que hoje se fala, nada mais é senão a incapacidade de poder ouvir o imediato com os próprios ouvidos, de poder tocar o intocado com as próprias mãos (ADORNO; HORKHEIMER, 1985, p. 41).
\end{abstract}

Por isso a importância da inclusão em Educação, como resistência ao que está posto na sociedade, ao propor com bravura "[...] Escolas centradas na criança são além do mais a base de treino para uma sociedade baseada no povo, que respeita tanto as diferenças quanto a dignidade 
de todos os seres humanos. Uma mudança de perspectiva social é imperativa" (UNESCO, 1994, p. 4. grifo nosso). Sawaia (2017) também nos leva a refletir sobre como os processos de inclusão e exclusão que acontecem cotidianamente na sociedade e nas instituições educacionais são contraditórios e complexos, indicando o movimento dialético e não a essencialidade que as palavras exclusão e inclusão assumem no cenário contemporâneo, como fenômenos de ordem social.

Dessa forma, evocar essas palavras na sala de aula com o apoio da professora e da turma, abre caminhos para a perlaboração, tensionando-as, remexendo e rompendo o "escudo protetor". Nesse sentido, Adorno enfatizou a relevância sócio-psicológica de se falar sobre um passado não superado. "O que, sem dúvida, importa realmente é a maneira pela qual o passado é tornado presente; se se permanece na mera recriminação ou se se resiste ao horror através da força de ainda compreender o incompreensível" (ADORNO apud. GAGNEBIN, 2006, p. 102).

Notadamente, perlaboração não significa esquecer o passado, pelo contrário, é a possibilidade de reconhecer, confrontar e compreender o dano e, assim, possibilitar uma experiência de ressignificação. Estamos lidando com um exercício que propõe uma nova relação consigo mesmo e com o outro, um amparo frente ao adormecimento do afeto e ao entorpecimento da habilidade de lidar com as diferenças.

Isso nos faz entender porque a memória pode desencadear vários enlaces: a memória como possibilidade de alteração do momento presente e do futuro, a memória como versão, memória como esquecimento; trata-se, portanto, de um elo que revela histórias, trajetórias, pessoas, limites e possibilidades que atravessam o ser humano e, portanto, o exercício da profissão docente.

O exercício de rememorar abre possibilidades de saber quem somos e quem nos tornamos a partir de nossas experiências de vida. Jorge Larrosa diz, em seu artigo Notas sobre a experiência e o saber da experiência:

A experiência é o que nos passa, o que nos acontece, o que nos toca. Não o que se passa, o que acontece, ou o que toca. A cada dia se passam muitas coisas, porém, ao mesmo tempo, quase nada nos acontece. Dir-se-ia que tudo o que se passa está organizado para que nada se nos passe (LARROSA, 2002, p. 21).

Esse Abecedário materializa em palavras os sentimentos que feriram de alguma forma esses/as professores/as, por isso refletir sobre essas experiências inclusivas/excludentes e ressignificar essa dor é olhar para si e para o outro, distanciando-se de uma formação instrumental que só diz o que fazer e aproximando-se de uma formação que olha pra dentro e se considera parte importante desse movimento, consolidando processualmente a formação na e para perspectiva inclusiva em si e no outro.

Considerando isso, refazer os laços, reestabelecer conexões essenciais à individuação, reconhecer injustiças históricas, resgatar as relações com as pessoas e consigo mesmo, dizem respeito à revolução da vida da qual a escola não pode se furtar.

\section{CONSIDERAÇÕES FINAIS}

Este artigo se configura como uma forma de demostrar a significância da Educação Física como componente curricular na Educação Básica, com amplas possibilidades de trabalhar questões que afetam nossa sociedade com criticidade e reflexão, mesmo numa disciplina que ainda carrega marcas de um histórico excludente e de desvalorização no chão da escola.

Um outro ponto fundamental é a materialização da luta pela educação pública e gratuita por meio do curso de Pós-graduação lato sensu que se volta a formar docentes na e para a perspectiva 
inclusiva, partindo de uma concepção ampla de inclusão, abarcando as complexidades e potencialidades das diferenças humanas, olhando para si e para o outro nesse jogo dialético. Posto isso, na tentativa de contribuírmos para a compreensão das relações entre Educação, Formação, Memória e Experiência, nos voltamos à construção e reflexão do Abecedário da Inclusão.

A construção do Abecedário da Inclusão por professores/as ganha uma dimensão muito maior, no sentido de que estamos lidando com a possibilidade de resistir a perpetuação da consciência reificada no processo de formação dos formadores, dando força, sentido e materialidade em um fazer político-pedagógico que se identifica e se relaciona com os valores humanitários da inclusão.

A mudança de mentalidade, de postura e de valor é um desafio. Entretanto, estamos certos de que, por meio da análise das palavras que compuseram nosso Abecedário da Inclusão, pudemos constatar o quão perigosa é a identificação acrítica e irrefletida da singularidade com a coletividade consolidada ideologicamente. Pois, é inegável que essas palavras foram proferidas em muitos outros espaços sociais e afetou muitas outras pessoas, causando muita dor e sofrimento.

No entanto, não é aceitável que, na conjuntura atual, prevaleça essa identificação que leva à perda da autonomia, de dignidade e do valor próprio. Por isso, é muito importante que a Educação fortaleça, no ser humano, o processo de tomada de consciência de si próprio, que cada um de nós se torne capaz de se perguntar "no que me tornei" e, a partir disso, refletir a respeito das razões pelas quais foram geradas tanta frieza e indiferença, para que possamos ser e fazer diferente! Como reconhecido por Adorno (2010, p. 185), "[...] aquele que quer transformar [a nossa realidade] provavelmente só poderá fazê-lo na medida em que converter esta impotência, ela mesma, justamente com a sua própria impotência, em um momento daquilo que ele pensa e talvez também daquilo que ele faz".

Nessas reflexões finais (por ora), ressaltamos a importância da produção de mais pesquisas no campo da inclusão, considerando essa perspectiva ampliada, tendo em vista avançar ainda mais nas questões sobre as diferenças e como estas nos afetam e afetam os outros.

Nesse sentido, esta pesquisa reforça a necessidade de se instituir formação pautada na perspectiva ampla de inclusão, considerando a relação entre formação e ação docente, no sentido de formar professores/as refletindo sobre sua própria prática, sobre suas próprias experiências, dialogando com outros sobre as práticas e experiências deles. Os principais resultados apontaram a necessidade de se elaborar as "marcas" das exclusões vividas no passado para que se possa admitir um porvir sem a reprodução de estereótipos, rótulos e preconceitos.

\section{REFERÊNCIAS}

ADORNO, Teodor. Educaşão e Emancipação. Rio de Janeiro: Paz e Terra, 2010.

ADORNO, Teodor; HORKHEIMER, Max. Dialética do esclarecimento: fragmentos filosóficos. Tradução de Guido de Antonio de Almeida, Rio de Janeiro: Jorge Zahar Ed., 1985.

ADORNO, Teodor. Escritos Sociológicos I. Tradução de Agustín González Ruiz. Obra completa, 8. ed. Madrid: Akal, 2004.

ALMEIDA, Silvio Luiz. O que é racismo estrutural? Belo Horizonte: Letramento, 2018

BENJAMIN, Walter. Passagens. Belo Horizonte: ed. UFMG. São Paulo: Imprensa oficial do Estado de São Paulo, 2006.

BENJAMIN, Walter. Magia e técnica, arte e politica: ensaios sobre literatura e história da cultura. Trad. Sérgio Paulo Rouanet. 7 ed. São Paulo: Brasiliense, 1994. 
BOLÍVAR, Antonio; DOMINGO, Jesus; FERNÁNDEZ, Manuel. La investigación biográfico-narrativa en educación. Madrid: La Muralla, 2001.

BOOTH, Tony; AINSCOW, Mel. Index para a Inclusão. Desenvolvendo a aprendizagem e a participação na escola. Produzido pelo LaPEADE, 2011.

CROCHICK, José Leon. Educação Inclusiva: subjetividade, preconceito e direitos humanos: qual sua relação. In. SILVA, Aida Maria Monteiro; COSTA, Valdelúcia Alves da (orgs.) Educação Inclusiva e Direitos Humanos: perspectivas contemporâneas. São Paulo: Cortez, 2015, p. 23-53.

CROCHICK, José Leon (org). Preconceito e Educaşão Inclusiva. 1. Ed. Brasília: Secretaria dos Direitos Humanos da Presidência da República, 2011.

FONSECA, Michele Pereira de Souza da. Inclusão: Culturas, políticas e práticas de inclusão na formação de professores de Educação Física da UFRJ. 262f. Dissertação (Mestrado em Educação). Faculdade de Educação, Universidade Federal do Rio de Janeiro, Rio de Janeiro, 2009.

FONSECA, Michele Pereira de Souza da. Formação de professores de Educação Física e seus desdobramentos na perspectiva dos processos de inclusão/ exclusão: reflexões sobre Brasil e Portugal. 202f. Tese (Doutorado em Educação). Faculdade de Educação, Universidade Federal do Rio de Janeiro, Rio de Janeiro, 2014.

GAGNEBIN, Jeanne Marie. Lembrar escrever esquecer. São Paulo: Editora. 34, 2006.

GÓIS JUNIOR, Edivaldo. Ginástica, higiene e eugenia no projeto de nação brasileira: Rio de Janeiro, século XIX e início do século XX. Revista Movimento. Porto Alegre, v.19, n.1, p.139- 159, jan/mar. 2013.

HORKHEIMER, Max. Eclipse da Razão. São Paulo: Centauro, 2002.

HORKHEIMER, Max. \& ADORNO, Teodor. Temas Básicos da Sociologia. São Paulo: Editora Cultrix, 1956.

LARROSA, Jorge. O ensaio e a escrita acadêmica. Educação e Realidade, Porto Alegre, v.28, n. 2, p.101-115, jul./dez. 2003a. Disponível em: http://seer.ufrgs.br/index.php/educacaoerealidade/article/view/25643/14981. Acesso em: 15 set. 2020.

LARROSA, Jorge. Pedagogia Profana: danças, piruetas e mascaradas. Belo Horizonte: Autêntica, 2003b.

LARROSA, Jorge. Notas sobre a experiência e o saber de experiência. Revista Brasileira de Educação. n.19, p. 20-28, Jan/Fev/Mar/Abr, 2002. Disponível em: https://www.scielo.br/pdf/rbedu/n19/n19a02.pdf. Acesso em: 16 set. 2020

NÓVOA, Antonio. Formação de professores e profissão docente. In: NÓVOA, Antonio (Org.). Os professores e a sua formação. 2. ed. Lisboa: Dom Quixote, 1995.

NÓVOA, Antonio. Formação de professores e trabalho pedagógico. Lisboa: EDUCA, 2002.

NÓVOA, Antonio. Firmar a posição como professor, afirmar a profissão docente. Cadernos de Pesquisa, v.47, n.166, p.1106-1133, out./dez. 2017. Disponível em: http://dx.doi.org/10.1590/198053144843. Acesso em: 20 set. 2020.

QUEIRÓS, Bartolomeu Campos. Correspondência. Rio de Janeiro: Rhj, 2004.

SAWAIA, Bader (Org.). As artimanhas da Exclusão: análise psicossocial e ética da desigualdade social. Petrópolis: Vozes, 2017.

UNESCO. Declaração de Salamanca. Necessidades Educativas Especiais - NEE In: Conferência Mundial sobre NEE. Salamanca/Espanha: UNESCO 1994. 
DOI: $10.12957 /$ teias.\%Y.54806

Submetido em setembro de 2020 Aprovado em marco de 2021

\section{Informações do(a)(s) autor(a)(es)}

Michele Pereira de Souza da Fonseca

Universidade Federal do Rio de Janeiro - UFRJ

E-mail: michelepsf22@gmail.com

ORCID: https://orcid.org/0000-0003-0355-2524

Link Lattes: http://lattes.cnpq.br/3628782671116228

Erika Souza Leme

Universidade Federal Fluminense - UFF

E-mail: erika.leme10@gmail.com

ORCID: http://orcid.org/0000-0002-8088-6002

Link Lattes: http://lattes.cnpq.br/5113929159975848 